\title{
A cementless elastic monoblock socket in young patients: a ten to 18-year clinical and radiological follow-up
}

\author{
Dean Pakvis • Liesbeth Biemond • \\ Gijs van Hellemondt $\cdot$ Maarten Spruit
}

Received: 7 July 2010 /Revised: 31 July 2010 /Accepted: 18 August 2010 /Published online: 5 September 2010

(C) The Author(s) 2010. This article is published with open access at Springerlink.com

\begin{abstract}
The survival of acetabular components depends on several factors: wear, osteolysis and septic or aseptic loosening. Osteolysis seems to be the main cause for concern in cementless arthroplasties. Acetabular osteolysis results from particle debris and segmental unloading of acetabular bone by rigid sockets. We investigated a cementless elastic monoblock socket with regard to acetabular osteolysis and aseptic loosening in a cohort of young patients. We evaluated 158 hip arthroplasties with a minimum follow-up of ten years (ten to 18 ) and a mean age of 42 years (18-50). The overall revision rate at 14 years was $80 \%$ with a $98 \%$ survival rate for aseptic loosening. The mean polyethylene wear rate was $0.11 \mathrm{~mm} /$ year. Progressive acetabular osteolysis was seen in $3 \%$ of patients evaluated. In conclusion, we found low pelvic osteolysis rates, acceptable overall wear rates, satisfactory overall survival and excellent survival rates for aseptic loosening of a cementless elastic monoblock socket in patients younger than 50 years. Ongoing tribology developments and knowledge about acetabular bone adaptations behind acetabular implants will further lower wear and osteolysis rates and optimise survival rates of cementless sockets.
\end{abstract}

\section{Introduction}

Although cementless sockets seem to be the primary option for young patients, there are not many reports presenting

D. Pakvis $(\bowtie) \cdot$ G. van Hellemondt $\cdot$ M. Spruit

Department of Orthopaedic Surgery, St. Maartenskliniek Hospital, P.O. Box 9011, 6500 GM Nijmegen, The Netherlands

e-mail: D.Pakvis@maartenskliniek.nl

L. Biemond

Department of Orthopaedic Surgery,

St. Radboud University Hospital,

Nijmegen, The Netherlands long-term survival data for cementless sockets in patients under 50 years [1-5]. Nearly all describe long-term results using rigid metal-backed acetabular systems.

In 1967 Robert Mathys Sr. developed the uncoated cementless RM elastic monoblock acetabular component (Fig. 1). This socket was based on the philosophy that the elastic modulus of the polyethylene RM socket (approximately $1,000 \mathrm{~N} / \mathrm{mm}^{2}$ ), in contrast to rigid metal shells (approximately $105.00 \mathrm{~N} / \mathrm{mm}^{2}$ ), mimics the elastic properties of acetabular bone (approximately $500-600 \mathrm{~N} / \mathrm{mm}^{2}$ ). The resulting physiological distribution of articular forces protects the acetabular bone and provides optimal conditions for ingrowth, and subsequent long-term component fixation. The purpose of this retrospective study was to evaluate the effect of the cementless elastic monoblock socket on acetabular osteolysis and long-term survival for aseptic loosening in young patients.

\section{Materials and methods}

During the period from 1990 to 1997, 158 hip arthroplasties were performed on 131 patients less than 50 years old. The mean age was 42.4 years (range 16-50); 67 were female and 64 were male. The indications for hip arthroplasty in this cohort are presented in Table 1.

A posterolateral approach was used in all patients, with direct full weight-bearing while allowing crutches during the first six weeks after surgery. The cementless RM monoblock (Mathys Ltd., Bettlach, Switzerland) socket was used in all patients. This monoblock socket is made from ultrahigh molecular weight polyethylene (UHMWPE) sterilised by gamma irradiation in air (Chirulen, ISO 5834/2 from GUR 1120, MediTECH, Vreden, Germany) with a heat pressed titanium coating using two anchoring pegs and 


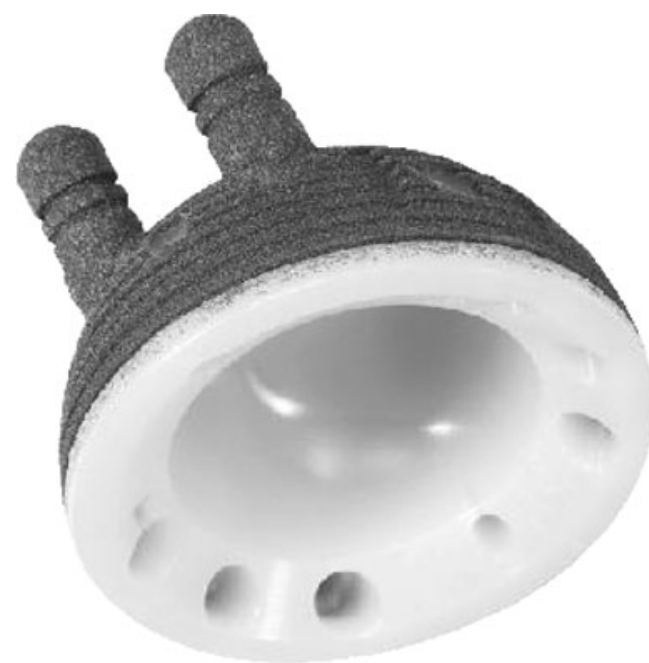

Fig. 1 Cementless Robert Mathys elastic monoblock socket

additional screw fixation for primary stability. In 99 hips a CLS Spotorno (Zimmer Ltd., Warsaw, IN, USA) femoral stem was used, 38 hips received an isoelastic RM (Mathys Ltd., Bettlach, Switzerland) stem, 16 hips a Wagner SL stem (Zimmer Ltd., Warsaw, IN, USA) and in five hips a Wagner cone stem (Zimmer Ltd., Warsaw, IN, USA) was implanted. All femoral heads were $28 \mathrm{~mm}$ with metal on PE articulation in 58 hips and ceramic on PE in 100 hips. All patients received perioperative antibiotics and deep vein thrombosis prophylaxis.

At the latest outpatient visit, all patients were clinically evaluated using the Harris hip score (HHS) and the Merle D’Aubigné/Postel questionnaires (Fig. 2). We defined an excellent to good clinical score as HHS of $100-80$ and Merle D'Aubigné/Postel of 18-14.

\section{Radiographic evaluation}

Observations and measurements were based on standardised anteroposterior pelvic and lateral hip radiographs made early in the postoperative period and at the latest follow-up visit. Correction of magnification was attained for all measurements using the femoral head. All radiographs were evaluated by two authors (DP, JB) and disagreements were resolved through consensus.

Socket migration was evaluated using the method described by Massin et al. [6]. Acetabular component migration of $>3 \mathrm{~mm}$ in the vertical or horizontal plane and change of cup inclination of $>8^{\circ}$ were classified as radiographically loose [7]. Wear was measured using methods described by Kang et al. [8]. Acetabular osteolysis was evaluated using the acetabular zones described by DeLee and Charnley [9]. It was deemed significant when progressive, measuring $>2 \mathrm{~mm}$ and occupying more than $50 \%$ of the acetabular zones. Heterotopic ossification (HO) was graded according to Brooker et al. [10].
Statistical analysis

We classified failure as revision of the acetabular component due to septic or aseptic loosening and PE wear. Survival analysis was calculated using the Kaplan-Meier method. We performed both best and worst case scenario analysis during the survival analysis. A logistic regression model was performed to evaluate the effect of patient age, gender, stem type, diagnosis, previous surgery and acetabular inclination on acetabular revision. Cox's proportional hazards model was used to examine the survival rates for different patient and component factors.

\section{Results}

The mean follow-up period was 13.2 years (range ten to 18). During this period, four patients (five hips) died without any relationship to the performed arthroplasty. Clinical and radiographic analysis showed no complications of their arthroplasty. Four patients were lost to follow-up, mainly due to emigration.

\section{Acetabular survivorship analysis}

During the study inclusion period 158 hip arthroplasties were performed in 131 patients. Acetabular revision had been performed on 20 patients by the latest follow-up. During our latest follow-up two patients were scheduled for acetabular revision. Our survival analysis was performed on the basis of $22(14 \%)$ acetabular revisions. The reasons for revision and additional data are listed in Table 2.

At ten years four patients $(3 \%)$ had undergone acetabular revision. At the time of the latest follow-up two patients (1\%) had undergone revision for aseptic loosening, two patients (1\%) for malposition and four patients $(3 \%)$ for trauma sequelae. In seven patients $(4 \%)$ acetabular wear was the primary reason for revision. During seven (4\%) femoral revisions the surgeon decided perioperatively to

Table 1 Preoperative diagnosis

\begin{tabular}{ll}
\hline & Hips $(N)$ \\
\hline Primary osteoarthritis & 46 \\
Secondary osteoarthritis & \\
Rheumatoid disease & 29 \\
Hip dysplasia & 38 \\
Osteonecrosis & 13 \\
Trauma & 16 \\
Other causes & 16 \\
Total & 158 \\
\hline
\end{tabular}




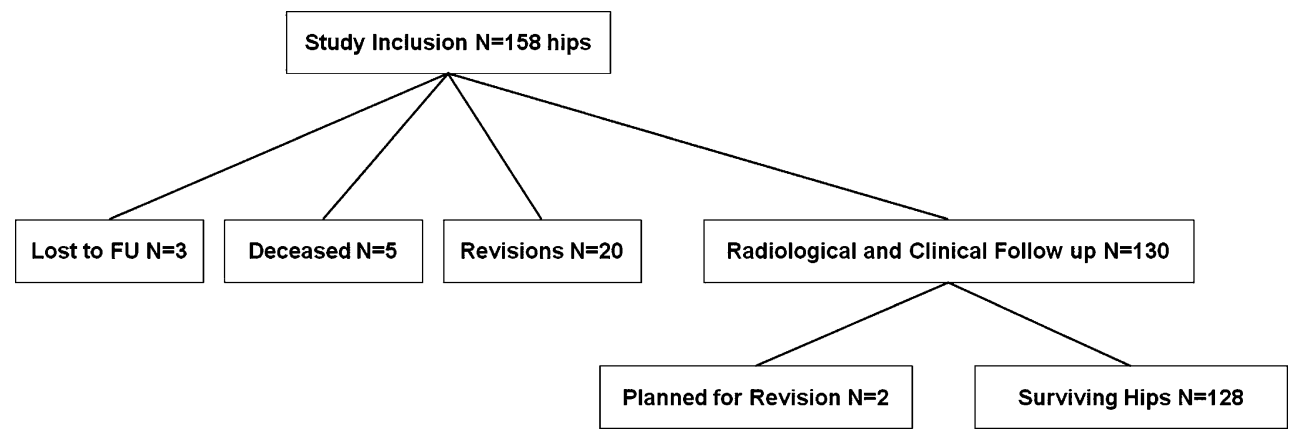

Fig. 2 Study inclusions

revise the acetabular component for minor to severe wear of the socket.

A worst case survival analysis showed $98 \%$ survival (95\% confidence interval: $95-100$ ) at ten years and $80 \%$ survival (95\% confidence interval: $72-89$ ) at 14 years (Fig. 3). Survival for aseptic loosening of the RM cup at ten and 14 years was $99 \%$ (95\% confidence interval: $98-100)$ and 98\% (95\% confidence interval: 96-100) (Fig. 4). Survival analysis for wear showed 99\% survival (95\% confidence interval: $98-100)$ at ten years and $86 \%$ survival (95\% confidence interval: 78-94) at 14 years follow-up. Wear analysis for the two featured articulations showed $80 \%$ survival (95\% confidence interval: 68-91) for the metal on $\mathrm{PE}$ articulations and $95 \%$ survival (95\% confidence interval: 87-100) for the ceramic on PE articulations at 14 years (Fig. 5).

Log-rank analysis for type of articulation and revision showed a statistical difference $(p=0.009)$ in favour of the

Table 2 Revision summary

\begin{tabular}{|c|c|c|c|c|c|c|c|c|}
\hline & Age & $\mathrm{M} / \mathrm{F}$ & Implantation & Indication & Revision & Indication & Articulation & Stem \\
\hline \multicolumn{9}{|l|}{ Case } \\
\hline 1 & 46 & M & $23-9-1992$ & Sec. & 28-9-1992 & Malposition cup & Metal-PE & $\mathrm{RM}$ \\
\hline 2 & 45 & M & 10-06-1994 & Prim. & $12-10-1994$ & Malposition cup & Ceramic-PE & CLS \\
\hline 3 & 43 & M & 21-4-1992 & Sec. & $9-1-1998$ & Trauma & Metal-PE & $\mathrm{RM}$ \\
\hline 4 & 46 & $\mathrm{~F}$ & $13-1-1993$ & Sec. & $15-4-1999$ & Aseptic loosening & Metal-PE & CLS \\
\hline 5 & 45 & M & $17-8-1992$ & Sec. & $19-2-2004$ & Wear $^{\mathrm{a}}$ & Metal-PE & RM \\
\hline 6 & 25 & M & $15-5-1990$ & Sec. & $8-4-2004$ & Wear $^{\mathrm{s}}$ & Metal-PE & RM \\
\hline 7 & 40 & M & 18-1-1994 & Sec. & $10-5-2004$ & Wear $^{\mathrm{b}}$ & Metal-PE & CLS \\
\hline 8 & 42 & $\mathrm{~F}$ & $24-2-1992$ & Sec. & $1-1-2005$ & Trauma & Metal-PE & $\mathrm{RM}$ \\
\hline 9 & 43 & $\mathrm{~F}$ & 30-11-1992 & Sec. & $20-1-2005$ & Wear $^{\mathrm{b}}$ & Metal-PE & CLS \\
\hline 10 & 28 & $\mathrm{~F}$ & 19-12-1991 & Sec. & $15-4-2005$ & Wear $^{\mathrm{a}}$ & Metal-PE & $\mathrm{RM}$ \\
\hline 11 & 49 & M & $22-6-1993$ & Sec. & $15-9-2005$ & Trauma & Metal-PE & CLS \\
\hline 12 & 47 & $\mathrm{~F}$ & $22-10-1993$ & Prim. & $4-11-2005$ & Wear $^{\mathrm{b}}$ & Metal-PE & CLS \\
\hline 13 & 29 & $\mathrm{~F}$ & 10-11-1992 & Sec. & $23-11-2005$ & Wear $^{\mathrm{a}}$ & Metal-PE & $\mathrm{RM}$ \\
\hline 14 & 48 & M & $21-6-1993$ & Prim. & $19-1-2006$ & Aseptic loosening & Metal-PE & CLS \\
\hline 15 & 25 & $\mathrm{~F}$ & 24-1-1994 & Sec. & $2-8-2006$ & Wear $^{\mathrm{b}}$ & Metal-PE & CLS \\
\hline 16 & 48 & M & 4-11-1992 & Prim. & $12-9-2006$ & Wear $^{\mathrm{a}}$ & Metal-PE & RM \\
\hline 17 & 46 & M & 10-11-1995 & Sec. & $12-9-2006$ & Trauma & Ceramic-PE & CLS \\
\hline 18 & 45 & M & 3-4-1995 & Sec. & $9-10-2006$ & Wear $^{\mathrm{b}}$ & Ceramic-PE & CLS \\
\hline 19 & 30 & $\mathrm{~F}$ & $13-4-1993$ & Sec. & $28-2-2007$ & Wear $^{\mathrm{b}}$ & Metal-PE & CLS \\
\hline 20 & 49 & M & 16-04-1993 & Prim. & $17-7-2007$ & Wear $^{\mathrm{a}}$ & Metal-PE & CLS \\
\hline 21 & 47 & $\mathrm{~F}$ & 28-12-1993 & Prim. & 20-08-2007 & Wear $^{\mathrm{b}}$ & Ceramic-PE & CLS \\
\hline 22 & 43 & M & 16-11-1992 & Sec. & 05-09-2007 & Wear $^{\mathrm{a}}$ & Metal-PE & CLS \\
\hline
\end{tabular}

${ }^{\text {a }}$ Primary reason for revision is femoral osteolysis with acetabular wear

${ }^{\mathrm{b}}$ Primary reason for revision is acetabular wear 


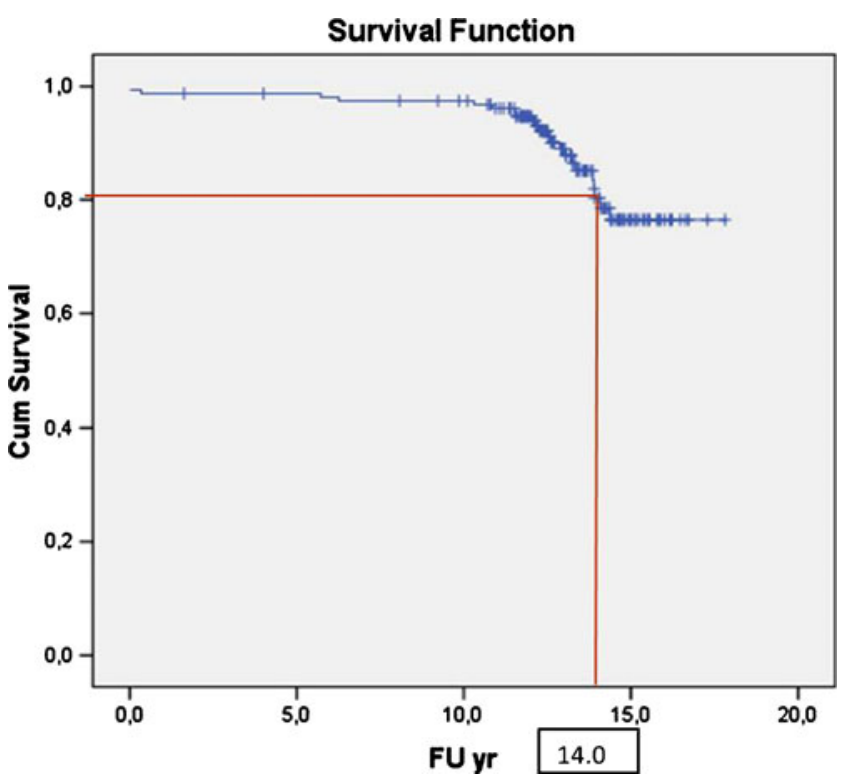

Fig. 3 Kaplan-Meier curve of the overall survival of the RM cup

ceramic on PE articulations. The Cox proportional hazards regression analysis showed a $6.8(1.5-30.5)$ times higher odds ratio for revision in a metal on PE articulation. A logistic regression model showed no effect on revision for factors including age, stem type, gender, diagnosis, previous surgery and acetabular inclination.

\section{Femoral revision}

During the follow-up period, 24 patients (15\%) underwent femoral revisions. Sixteen RM stems, six CLS stems and two Wagner stems had been revised prior to the follow-up.

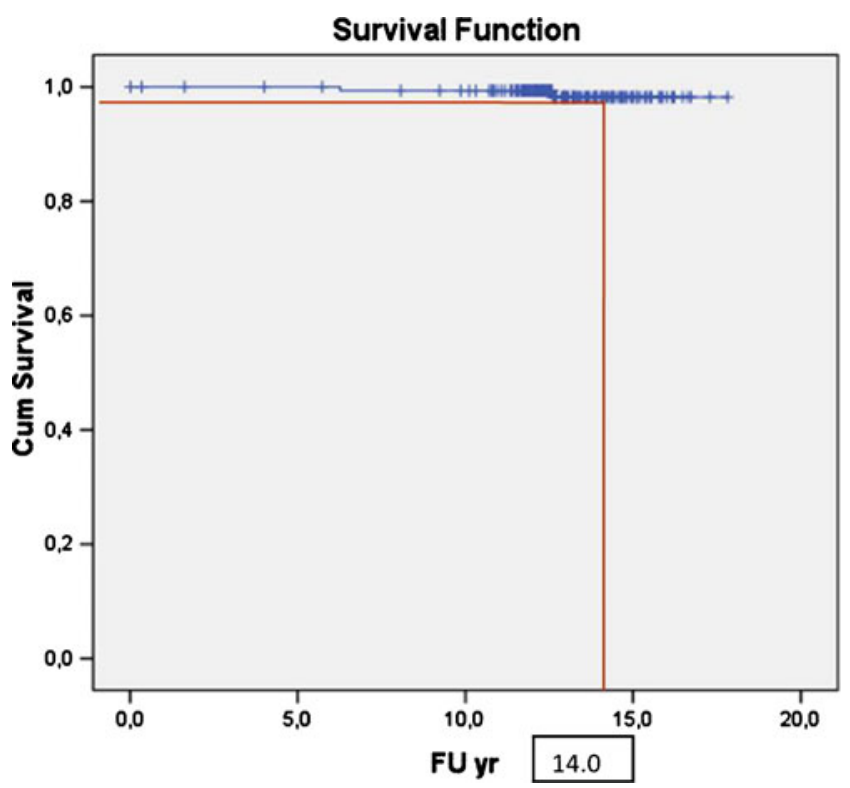

Fig. 4 Kaplan-Meier curve of survival rate for aseptic loosening of the RM cup
During seven of these procedures, acetabular revision was simultaneously performed due to wear of the monoblock RM system. All patients who underwent exclusively a femoral revision remained in the survival analysis for the RM acetabular component.

\section{Clinical results}

Of the remaining 130 hip arthroplasties, 102 (79\%) had excellent to good HHS. At the latest clinical evaluation, nine patients $(7 \%)$ showed fair and $19(15 \%)$ had poor results. Only 11 patients $(9 \%)$ showed poor clinical results using the Merle D'Aubigné/Postel questionnaire. All other patients achieved excellent to good scores on the Merle D’Aubigné/Postel questionnaire.

\section{Radiographic results}

Pelvic radiographs were available for all patients who were not lost to follow-up and who were still alive. In Table 3 radiographic parameters are shown comparing the revised group with the non-revised group. At the final follow-up three sockets showed a significant advancement in inclination and also showed significant horizontal and vertical migration. Two patients showed only a significant vertical migration.

Two patients were considered as outliers for horizontal and vertical migration $(5.0 \mathrm{~mm}, 10.5 \mathrm{~mm}$ and $10.5 \mathrm{~mm}$, $32.5 \mathrm{~mm}$, respectively). The first patient showed excellent clinical scores with significant wear and refused revision due to lack of symptoms. The second patient had a poor clinical score, showed significant wear but refused revision. We analysed the migration patterns for the two articulations

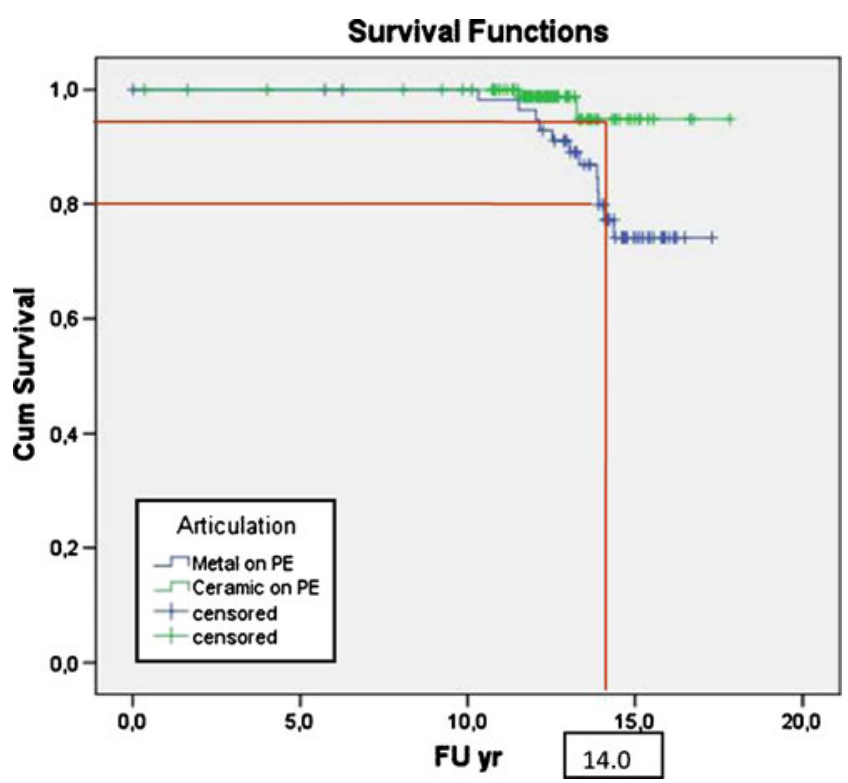

Fig. 5 Kaplan-Meier curve for wear of the RM cup and articulation type 
Table 3 Radiological evaluation

\begin{tabular}{llllll}
\hline & \multicolumn{2}{l}{ Non-revised sockets } & & \multicolumn{2}{l}{ Revised sockets } \\
\cline { 2 - 3 } \cline { 5 - 6 } & Postoperative & At follow-up & & Postoperative & Before revision \\
\hline Patient numbers & $N=130$ & $N=130$ & & $N=20$ & $N=20$ \\
Inclination (range) & $35^{\circ}(10-63)$ & $35(10-60)$ & $37^{\circ}(18-62)$ & $37^{\circ}(19-63)$ \\
Migration horizontal & & $1.9 \mathrm{~mm}$ & & $1.4 \mathrm{~mm}$ \\
Migration vertical & & $2.4 \mathrm{~mm}$ & & $0.16 \mathrm{~mm} /$ mear (range 0.02-0.46) \\
Wear (Kang et al. [8]) & & $0.11 \mathrm{~mm} /$ year (range 0-0.68) & & $0.16 \mathrm{~mm}$ \\
\hline
\end{tabular}

used in our study. All reported outliers mentioned above were patients with a ceramic on PE articulation. We found no statistical difference for either horizontal (mean: $1.5 \mathrm{~mm} ; 1.9 \mathrm{~mm}$ ), vertical (mean: $1.8 \mathrm{~mm} ; 2.3 \mathrm{~mm}$ ) and inclination (mean: $2.3^{\circ} ; 2.8^{\circ}$ ) migration for, respectively, the metal on PE and ceramic on PE articulations. Heterotopic ossification, HO was seen in 46 patients (grade $1=18$, grade $2=11$, grade $3=15$, grade $4=2$ ). Significant progressive acetabular osteolysis was seen in four patients (3\%), mainly cavitary osteolysis found in DeLee and Charnley zone 1 adjacent to the fixation screws.

\section{Complications}

In our cohort seven arthroplasties (4\%) had one or more dislocations, two of which required simultaneous acetabular and femoral revision and in three cases in isolated femoral stem revisions. There were three infections for which one patient underwent operative débridement. Femoral fractures were seen in six cases: three during implantation and three during the follow-up period. One patient showed sciatic nerve irritation due to a postoperative haematoma; the symptoms resolved following conservative treatment. Surgical treatment was indicated for two patients suffering from grade $4 \mathrm{HO}$. Two patients had postoperative urinary tract infections which were treated with oral antibiotics.

\section{Discussion}

Total hip arthroplasty (THA) is a very successful orthopaedic procedure [11], but there is no consensus in defining the optimal socket fixation method, especially for young patients [12]. Although cementless sockets are often advocated in young patients, patients younger than 50 years are more susceptible to wear, osteolysis, implant loosening and failure because of their increased activity level [13-15]. Publications specifically investigating longterm results for a homogeneous group of cementless sockets in patients under 50 years are scarce. McLaughlin and Lee reported a 56\% revision rate at ten years using the T-Tap socket in patients aged 50 years or less [1]. Comparable results were published by Utting et al. who reported 55\% impending Harris-Galante I revisions at a mean follow-up of 13.6 years for patients with a mean age of 40 years [4]. The same socket was used by Crowther and Lachiewicz and Duffy et al., both with better survival rates of 98 and $88 \%$, respectively, at ten years in young patients [2, 3]. Kim et al. implanted 102 Duraloc Option acetabular components in 73 patients with a mean age of 38 years [5]. They reported a cumulative acetabular survival of $99 \%$ at 11 years.

All these publications, however, concern long-term results of modular acetabular systems.

In a review of the Finnish Arthroplasty Register in 2008, Mäkelä et al. raised concerns about wear-related revisions for modular cementless sockets [16]. The authors emphasised this problem because of the high proportion of reported liner/wear-related problems. In 2002 Young et al. reported a comparative study between modular and monoblock systems, both using PE sterilised by gamma irradiation in air [17]. In that study the monoblock system demonstrated a lower mean true wear rate and significantly $(p=0.01)$ less osteolysis. Liner-shell conformity, optimisation of clearance, increased polyethylene thickness, absence of a locking mechanism and no liner-shell micromotions (backside wear) are factors in favour of monoblock systems.

The PE that had been gamma irradiated in air, which we used in our study, showed a mean articular wear of $0.11 \mathrm{~mm} /$ year. These values correspond well with articular wear in the literature on cementless modular sockets $(0.08$ and 0.18$)$ [18, 19], monoblock sockets $(0.05-0.17)$ [20, 21] and even cemented sockets in young patients (0.06 and 0.12) [22, 23]. In our study, approximately one third of the articulations used were metal on PE. In accordance with other authors $[21,24,25]$, this resulted in an increased risk for revision for PE wear with a survival of $80 \%$ (95\% confidence interval: 68-91) at 14 years compared with a superior long-term survival rate of $95 \%$ (95\% confidence interval: $86.8-100)$ for a ceramic on PE articulation. The ceramic on PE articu- 
lations showed a non-significantly higher mean migration rate mainly due to the several outliers found in our analysis.

Seven sockets were revised during femoral revision surgery. Regional acetabular PE wear was estimated to range from minor to severe during femoral revision surgery although during preoperative planning there was no intention to perform an acetabular revision. The decision to revise the acetabular component was simplified due to the relative ease with which the socket can be revised. Nearly all known monoblock sockets are made by fixing a $\mathrm{PE}$ liner into a rigid metal shell during fabrication. In cases of an impending revision, the all poly construction of the RM socket has the advantage over these metal-shelled monoblock sockets due to its relatively easy revision method [26, 27]. Using an acetabular reamer and sufficient irrigation, the socket can be removed with the least amount of acetabular bone stock damage.

Almost all instances of progressive periacetabular osteolysis seen on the pelvic radiographs were cavitary osteolytic lesions mainly found in DeLee and Charnley zone 1. This could be explained by the adjacent screw which can act as a pathway for PE particles.

The osteolysis rates found in our study of the RM socket compare favourably to data reported on cementless acetabular components $[17,28]$ and are comparable to the known low osteolysis rates for monoblock sockets [21, 29].

The concept of a coated elastic monoblock socket has remained unique. The advantage of this concept is the osseointegration potential of the titanium coating which does not affect the elastic properties of the socket. The elastic modulus of the socket permits transmission of physiological articular stresses and thereby reduces acetabular stress shielding and the development of acetabular osteolysis.

In 2008 Ihle et al. reported the longest follow-up for an RM socket [24]. They presented data on 93 consecutive RM sockets at a mean follow-up of 19 years. Cumulative acetabular survival analysis for any reason showed an excellent survival rate of $83 \%$ (95\% confidence interval: 73-90) at 20 years. Regression analysis showed a fourfold risk for acetabular revision in younger patients.

A worst case survival analysis of the 158 hip arthroplasties reported in our study showed the somewhat lower survival of $80 \%$ (95\% confidence interval: $72-89)$ at 14 years. The patients presented in our study, however, had a lower mean age (42 vs 52) and there were more metal on PE articulations which resulted in more wear and revisions.

This study presents long-term follow-up data relating to a cementless elastic monoblock socket in a large cohort of young patients with a nearly complete clinical and radiological follow-up. A drawback of this study is the retrospective design, two different articulation types and the different stem types used which both interfere with determining the survival of the RM socket alone. Although this study has limitations, our report shows good clinical outcome, low osteolysis rates and excellent long-term survival rates for aseptic loosening of a cementless elastic socket in young patients.

Ongoing tribology developments and knowledge concerning acetabular bone adaptations behind acetabular implants will further lower wear and osteolysis rates and could optimise survival rates of cementless sockets.

Acknowledgements The authors would like to gratefully acknowledge P.G. Anderson for her statistical knowledge and assistance in this manuscript.

Conflict of interest The authors declare that they have no conflict of interest.

Open Access This article is distributed under the terms of the Creative Commons Attribution Noncommercial License which permits any noncommercial use, distribution, and reproduction in any medium, provided the original author(s) and source are credited.

\section{References}

1. McLaughlin JR, Lee KR (2000) Total hip arthroplasty in young patients. 8- to 13-year results using an uncemented stem. Clin Orthop Relat Res 373:153-163

2. Crowther JD, Lachiewicz PF (2002) Survival and polyethylene wear of porous-coated acetabular components in patients less than fifty years old: results at nine to fourteen years. J Bone Joint Surg Am 84:729-735

3. Duffy GP, Prpa B, Rowland CM, Berry DJ (2004) Primary uncemented Harris-Galante acetabular components in patients 50 years old or younger: results at 10 to 12 years. Clin Orthop Relat Res 427:157-161

4. Utting MR, Raghuvanshi M, Amirfeyz R, Blom AW, Learmonth ID, Bannister GC (2008) The Harris-Galante porous-coated hemispherical, polyethylene-lined acetabular component in patients under 50 years of age: a 12- to 16-year review. J Bone Joint Surg Br 90:1422-1427

5. Kim Y-H, Choi Y, Kim JS (2009) Cementless total hip arthroplasty with ceramic-on-ceramic bearing in patients younger than 45 years with femoral-head osteonecrosis. Int Orthop [Epub ahead of print]. doi:10.1007/s00264-009-0878-y

6. Massin P, Schmidt L, Engh CA (1989) Evaluation of cementless acetabular component migration. An experimental study. J Arthroplasty 4:245-251

7. Engh CA, Griffin WL, Marx CL (1990) Cementless acetabular components. J Bone Joint Surg Br 72:53-59

8. Kang JS, Park SR, Ebramzadeh E, Dorr LD (2003) Measurement of polyethylene wear in total hip arthroplasty-accuracy versus ease of use. Yonsei Med J 44:473-478

9. DeLee JB, Charnley J (1976) Radiological demarcation of cemented sockets in total hip replacement. Clin Orthop Relat Res 121:20-32

10. Brooker AF, Boweman JW, Robinson RA, Riley LH Jr (1973) Ectopic ossification following total hip replacement. Incidence and a method of classification. J Bone Joint Surg Am 55:1629 1632

11. Learmonth ID, Young C, Rorabeck C (2007) The operation of the century: total hip replacement. Lancet 370:1508-1519 
12. Eskelinen A, Remes V, Helenius I, Pulikkinen P, Nevalainen J, Paavolainen P (2005) Total hip arthroplasty for primary osteoarthrosis in younger patients in the Finnish arthroplasty register. 4,661 primary replacements followed for 0-22 years. Acta Orthop 76:28-41

13. Furnes O, Lie SA, Espehaug B, Vollset SE, Engesaeter LB, Havelin LI (2001) Hip disease and the prognosis of total hip replacements. A review of 53,698 primary total hip replacements reported to the Norwegian Arthroplasty Register 1987-99. J Bone Joint Surg Br 83:579-586

14. Kim YH, Oh SH, Kim JS (2003) Primary total hip arthroplasty with a second-generation cementless total hip prosthesis in patients younger than fifty years of age. J Bone Joint Surg Am 85:109-114

15. Kearns SR, Jamal B, Rorabeck CH, Bourne RB (2006) Factors affecting survival of uncemented total hip arthroplasty in patients 50 years or younger. Clin Orthop Relat Res 453:103-109

16. Mäkelä KT, Eskelinen A, Pulikkinen P, Paavolainen P, Remes V (2008) Total hip arthroplasty for primary osteoarthritis in patients fifty-five years of age or older. An analysis of the Finnish arthroplasty registry. J Bone Joint Surg Am 90:2160-2170

17. Young AM, Sychterz CJ, Hopper RH Jr, Engh CA (2002) Effect of acetabular modularity on polyethylene wear and osteolysis in total hip arthroplasty. J Bone Joint Surg Am 84:58-63

18. Ito H, Matsuno T, Aok Y, Minami A (2004) Total hip arthroplasty using an Omniflex modular system: 5 to 12 years followup. Clin Orthop Relat Res 419:98-106

19. Krieg AH, Speth BM, Ochsner PE (2009) Backside volumetric change in the polyethylene of uncemented acetabular components. J Bone Joint Surg Br 91:1037-1043

20. Hinrichs F, Boudriot U, Held T, Griss P (2001) 10 years results with a Monobloc hip endoprosthesis cup with multilayer titanium mesh coating for cement-free implantation (in German). Z Orthop Ihre Grenzgeb 139:212-216

21. Berli BJ, Ping G, Dick W, Morscher EW (2007) Nonmodular flexible press-fit cup in primary total hip arthroplasty: 15-year followup. Clin Orthop Relat Res 461:114-121

22. Wroblewski BM, Siney PD, Fleming PA (2009) Charnley lowfrictional torque arthroplasty: follow-up for 30 to 40 years. J Bone Joint Surg Br 91:447-450

23. Ballard WT, Callaghan JJ, Sullivan PM, Johnston RC (1994) The results of improved cementing techniques for total hip arthroplasty in patients less than fifty years old. A ten-year follow-up study. J Bone Joint Surg Am 76:959-964

24. Ihle M, Mai S, Pfluger D, Siebert W (2008) The results of the titanium-coated RM acetabular component at 20 years: a longterm follow-up of an uncemented primary total hip replacement. J Bone Joint Surg Br 90:1284-1290

25. D'Antonio JA, Sutton K (2009) Ceramic materials as bearing surfaces for total hip arthroplasty. J Am Acad Orthop Surg 17:63-68

26. Mallory TH, Lombardi AV Jr, Fada RA et al (2000) Noncemented acetabular component removal in the presence of osteolysis: the affirmative. Clin Orthop Relat Res 381:120-128

27. Horne G, Devane PA, Dalton DJ (2006) Does pelvic osteolysis occur with a nonmudular uncemented acetabular component? J Arthroplasty 21:185-190

28. Della Valle CJ, Mesko NW, Quigley L, Rosenberg AG, Jacobs JJ, Galante JO (2009) Primary total hip arthroplasty with a porouscoated acetabular component. A concise follow-up, at a minimum of twenty years, of previous reports. J Bone Joint Surg Am 91:1130-1135

29. Macheras G, Kateros K, Kostakos A, Koutsostathis S, Danomaras D, Papagelopoulos PJ (2009) Eight- to ten-year clinical and radiographic outcome of a porous tantalum monoblock acetabular component. J Arthroplasty 24:705-709 